\title{
Bebês no coletivo da creche: encontros e provocações redimensionando o fazer pedagógico
}

Carolina Gobbato Universidade Estadual do Rio Grande do Sul - Brasil

Maria Carmen Silveira Barbosa Universidade Federal do Rio Grande do Sul - Brasil

\section{Resumo}

A partir da problematização do (des)lugar dos bebês na creche, o artigo tem como objetivo discutir como a presença de um grupo de berçário nos espaços de uso comum de uma escola de educação infantil do RS pode implicar redimensionamentos pedagógicos. As análises revelaram que as ações e relações dos bebês nos diferentes espaços da creche dão visibilidade à ação pedagógica e trazem provocações acerca do modo como a escola está organizada. Considera-se que habitar espaços coletivos da creche amplia e complexifica as aprendizagens dos bebês, fomentando pedagogias que acolham as suas especificidades.

Palavras-chave: Educação infantil. Creche. Bebês. Espaços.

\section{Bebés en el colectivo de la guardería: encuentros y pro- vocaciones redimensionando el hacer pedagógico}

\section{Resumen}

A partir de la problematización del (no) lugar de los bebés en la guardería, el artículo tiene como objetivo discutir cómo la presencia de un grupo de bebés en los espacios de uso común de una escuela infantil del RS puede implicar redimensionamientos pedagógicos. Los análisis revelaron que las acciones y relaciones de los bebés en la guardería dan visibilidad a la acción pedagógica y traen provocaciones acerca del modo en que la escuela está organizada. Se considera que habitar espacios colectivos de la guardería amplía y compleja los aprendizajes de los bebés, fomentando pedagogías que acojan sus especificidades.

Palabras clave: Educación Infantil. Guardería. Bebés. Espacios. 


\title{
Babies in the kindergarten collective group: meetings and provocations redirecting the pedagogy duties
}

\begin{abstract}
Starting from the problem discussion of the (un) place of the babies in the kindergarten, the article has as goal discuss how the presence of a nursery group in the childhood school's usual spaces in RS can affect pedagogy redirecting. The analysis revealed that the actions and relations of the babies at the different kindergarten's spaces gives visibility to the pedagogy action and bring provocations about the way how the school is organized. It's considered that use the kindergarten's collective environment expand and get complex for the babies learning, increasing pedagogies that hold your specifies.
\end{abstract}

Key- words: Childhood school. Kindergarten. Babies. Spaces.

\section{Les bébés dans le collectif de la crèche : rencontres et provocations qui redimensionnent le faire pédagogique}

\section{Résumé}

À partir de la problématisation du lieu (ou l'absence de) des bébés dans la crèche, l'article a pour but discuter comment la présence de bébés dans les espaces d'usages communs dans une garderie de RS peut entraĩner à redimensionner des pédagogies. Les analyses révélèrent que les actions et les relations des bébés dans les différents espaces de la crèche donnent visibilité à l'action pédagogique et apportent des provocations sur l'organisation de l'école. On considère qu'habiter des espaces collectifs de la crèche amplifie et complexifie les apprentissages des bébés, incitant à des pédagogies pour en accueillir ses spécificités.

Mots-clés: Éducation des enfants. Crèche. Bébés. Espaces.

\section{Introdução: (des)lugar dos bebês na creche}

A invisibilidade do estatuto social das crianças e dos bebês construiu imagens de infância que por muito tempo obscureceram suas potencialidades (Sarmento, 2007). No campo da educação, é possível identificar a repercussão desse fato histórico no (des)lugar dos bebês na educação infantil - seja em nível macro, com a sua ausência no âmbito das políticas públicas, seja em nível micro, com a sua expressão 
em vivências nas instituições pautadas pela não participação dos bebês (Gobbato \& Barbosa, 2017).

Em muitas instituições, são os bebês que precisam se adaptar ao ritmo e às propostas das escolas de educação infantil. Estas costumam ser desenvolvidas visando às crianças maiores, em vez de ofertarem práticas pedagógicas que contemplem as especificidades das menores. Pesquisas nacionais (Schmitt, 2008; Simiano, 2010) revelaram que os bebês não participavam das propostas nas escolas infantis em que ocorreram as investigações. Eles quase não frequentavam os espaços de uso comum da instituição ao longo do ano, e o espaço do berçário era visto como um ambiente que separava os bebês da creche como um todo.

O uso privilegiado do espaço interno da creche - especialmente o da sala dos grupos de bebês e de crianças bem pequenas ${ }^{1}$ — talvez possa ser explicado pela compreensão equivocada deste como um espaço de fácil controle quanto às questões de segurança, higiene e limpeza. Em outras palavras, a sala do berçário é vista como um espaço onde se torna mais simples assegurar cuidados de proteção com relação à vida e à saúde dos bebês. Essa concepção de espaço nos parece ainda influenciada pelo discurso higienista e pela puericultura na estruturação e no uso dos espaços das creches brasileiras, implicando o oferecimento do espaço interno aos pequenos, em detrimento do externo (Barbosa, 2006).

Na tendência contextualizada acima, os solários configuram-se como os principais locais de saída dos bebês da sua sala, quando ela ocorre, caracterizando-se como locais anexos a ela. Eles costumam estar isolados dos outros pátios da escola e se caracterizam como cenários semelhantes ao espaço interno - por exemplo, com mesmo piso, cheiros, brinquedos de plástico. Os "Parâmetros básicos de infraestrutura para instituições de educação infantil”, publicados pelo Ministério da Educação (MEC), apontaram que em muitas instituições de educação infantil no Brasil inexistem áreas externas ou espaços alternativos às salas (Brasil, 2006).

Além dos aspectos relacionados à higiene e à infraestrutura pouco adequada, acreditamos que a compreensão da sala como espaço por excelência do bebê na escola infantil relaciona-se também ao pouco reconhecimento da importância de proposições pedagógicas para a faixa etária de 0 a 2 anos. Há uma dificuldade em operacionalizar na prática o que estudos sobre a educação de bebês vêm apontando em relação à creche como um lugar de acolhida e de experiências dos bebês na vida coletiva.

A justificativa para esse (des)lugar dos bebês nos espaços coletivos da creche é, muitas vezes, pautada no discurso da incompletude e da imaturidade, distanciando-

1 Bebês são crianças de 0 a 18 meses; crianças bem pequenas são aquelas entre 19 meses e 3 anos e 11 meses; crianças pequenas são aquelas entre 4 anos e 6 anos e 11 meses; crianças maiores são as entre 7 e 12 anos incompletos (Barbosa, 2009). 
se do conceito de criança como sujeito de direito e capaz de participar dos contextos em que vive. Nessa perspectiva, "[os] bebês precisariam aprender a andar primeiro, passando a frequentá-los [os espaços coletivos], então, só quando eles estivessem "prontos', completos e quando fossem capazes" de habitar os espaços para além da sala do berçário (Simiano, 2010, p.106).

Percebemos aqui que há um jogo antagônico de compreensões acerca das vivências dos bebês nas escolas infantis. Prevalece uma concepção de que eles são inaptos à vida e à circulação nos espaços coletivos das instituições, e não o contrário - de que os espaços da creche é que não estão suficientemente planejados para acolher os bebês e as suas singularidades. Essa exclusão dos bebês do campo educacional (e dentro da creche) relaciona-se com um processo maior de invisibilidade dos bebês em outros setores e espaços da sociedade, conforme afirmou Rosemberg (2015a) ao apontar que as crianças de 0 a 3 anos "[...] constituem um tempo social discriminado pela sociedade latino-americana, na gestão e nas políticas públicas [...]” (p. 165).

Em decorrência disso, um paradoxo se apresenta: ao mesmo tempo em que estamos propiciando aos bebês a experiência de estar no ambiente coletivo das creches, lutando pela ampliação das vagas e entendendo que é o seu direito, estamos confinando as suas vivências a um espaço relativamente pequeno em relação ao montante do espaço institucional: o da sala.

Tendo em vista a problematização desse (des) lugar dos bebês no coletivo da creche, dos lugares que eles não vêm ocupando na instituição de educação infantil e das propostas nas quais eles são frequentemente pouco contemplados, o presente artigo tem como objetivo discutir como a presença de um grupo de bebês nos espaços de uso comum da creche pode implicar possíveis redimensionamentos do fazer pedagógico com essa faixa etária, a partir da análise dos dados de uma pesquisa realizada com um grupo de berçário.

\section{Percursos metodológicos e contexto investigado}

O material empírico analisado neste trabalho compõe o acervo de dados de uma pesquisa de mestrado², que foi desenvolvida com um grupo de berçário em uma escola pública de educação infantil do Rio Grande do Sul. No período de março a julho de 2010, acompanhamos as rotinas do berçário 1: os bebês desse grupo circulavam e se faziam presentes por quase todos os espaços de uso coletivo da instituição pesquisada cotidianamente.

O grupo do berçário era composto por 15 bebês com idades entre 4 e 18 meses

$2 \quad$ Trata-se da pesquisa de Mestrado intitulada "Os bebês estão por todos os espaços: um estudo sobre a educação de bebês nos diferentes contextos de vida coletiva da escola infantil" (GOBBATO, 2011). 
no início do estudo e as suas educadoras - uma professora e quatro auxiliares ${ }^{3}$. Com a imersão no dia a dia da creche, escolhemos como principal procedimento metodológico a observação, que nos ofereceu a possibilidade de compreender os significados produzidos e comunicados no contexto pesquisado (Tura, 2003).

Ao investigar as práticas cotidianas do grupo do berçário em diversos espaços da instituição, as perguntas que guiaram nossa observação foram: quais as ações e relações que se estabelecem quando os bebês estão nos diferentes espaços da instituição? De que forma os bebês e os adultos problematizam o modo de organização desses espaços? Quais implicações de cunho coletivo podem ser identificadas com a presença da turma do berçário nos espaços da creche? Como o uso dos diferentes espaços redimensiona a ação pedagógica do berçário?

No período observado, percebemos investimento por parte das profissionais da escola quanto à saída dos bebês do espaço da sala do berçário. Elas fizeram desta uma prática não eventual na rotina do grupo, pois os bebês frequentavam os seguintes espaços: refeitório, pátios (da frente, do meio 1, do meio 2), corredores, biblioteca e brinquedoteca. Para a professora, "[...] os bebês têm que ir a todos os lugares, viver [...] experimentar tudo! Experimentar todos os espaços, explorar todos os espaços, ver o que é que os espaços podem oferecer para eles" (Diário de Campo, 25 de junho, 2010). Destacamos a relevância da compreensão da professora acerca de quem são os bebês e suas competências para a consolidação da prática pedagógica que realiza - bebês que exploram o mundo. Além disso, também percebemos que está presente em sua fala uma concepção de espaço que é "potente" - um espaço que traz ofertas aos bebês e amplia suas experiências.

Durante a pesquisa, além de observar, realizamos conversas-entrevistas com as profissionais da instituição, considerando que todo processo de entrevista implica uma construção conjunta, na qual vamos fazendo ajustes, retomando perguntas, estabelecendo diálogos (Zago, 2003). Abaixo apresentamos um trecho de uma conversa-entrevista realizada com a coordenadora da instituição, a qual nos permitiu contextualizar o trabalho pedagógico desenvolvido com a turma de berçário na escola:

Antes os educadores tinham muito medo de sair com os bebês da sala, como se os bebês dormissem a tarde toda! Antigamente era só a sala que era ambiente dos bebês! Eu vim para cá de uma escola que o berçário tinha um pátio pequeno para eles. Isso é ruim, não é bom! Tu separa os bebês. Numa estrutura antiga [...] pensa bem, as crianças não se veem durante o dia! Às vezes, têm dois ou três irmãos e passam o dia inteiro sem se verem na escola. Antes, aqui na escola, tinha festa separada dentro da sala para o berçário 1, mas as crianças têm que conviver. Se convivem em casa, por que não podem conviver aqui?

(Diário de Campo, 06 de junho, 2010)

3 De acordo com as combinações feitas com os sujeitos participantes da pesquisa e os responsáveis pelas crianças, utilizamos nomes fictícios neste trabalho. 
Na narrativa da Coordenadora está presente a sua preocupação com as relações e interações das crianças nos espaços coletivos da creche, como apontado nas "Diretrizes curriculares nacionais para a educação infantil" - DCNEl (Brasil, 2009), bem como o seu entendimento pedagógico sobre as possibilidades de experiências desses espaços, quando o acesso é ofertado aos bebês. Estarmos imersas na escola, observando e conversando com as profissionais, possibilitou-nos construir um percurso metodológico fundamental para interpretar os motivos pelos quais os bebês eram levados aos outros espaços da instituição, bem como as dificuldades e possibilidades que decorriam dessa vivência, compreendendo as ações e relações dos bebês nos contextos de vida coletiva da creche.

\section{Os espaços coletivos da creche como contextos habitados pelos be- bês}

Discutir os locais de uso coletivo da instituição de educação infantil como contextos em que os bebês também podem habitar requer pensá-los como espaços que educam e que devem ser intencionalmente planejados. Assim, é preciso levar em consideração o direito dos bebês de estar neles e de participar das propostas da instituição. Para tanto, embasamo-nos na compreensão de que a creche e a pré-escola fornecem um horizonte mais amplo, no qual o bebê e a criança pequena inscrevem as suas vidas — um mundo social (Sarmento, 2007). Trata-se de um lugar onde as crianças podem ter as suas experiências ampliadas e complexificadas, em um dos primeiros espaços coletivos de participação.

É o reconhecimento da opção pedagógica da oferta de contextos de experiências e da ampliação dos repertórios das crianças como características da identidade da educação infantil (Brasil, 2009) que fundamenta o planejamento de espaços instigantes e acolhedores para todos. Os espaços não são apenas "panos de fundo", mas sim contextos importantes, que oferecem possibilidades às crianças: são um elemento pedagógico. Com os grupos de bebês, isso se intensifica ainda mais, uma vez que é por meio das intervenções do educador no espaço físico que se colocam desafios que complexificam as experiências deles, pois a organização do espaço constitui uma intervenção pedagógica indireta feita pelo professor (Barbosa, 2006).

Ainda que planejá-los seja imprescindível, é no uso compartilhado dos espaços pelas dinâmicas sociais e culturais que ali acontecem - que bebês e adultos vão reconfigurando esses espaços e tornando-os contextos de vida coletiva, construindo culturas. Nessa perspectiva, Moss e Petrie (2002 apud Vasconcelos, 2007) falam de "espaços da infância", e não de "espaços para a infância". Eles os descrevem como espaços físicos (certamente), mas que são ao mesmo tempo sociais, culturais, discursivos, nos quais as crianças encontram-se com seus pares e com adultos e são reconhecidas como cidadãs com direitos, membros participantes dos grupos sociais de que fazem parte. 
Se compreendermos a creche como um desses espaços da infância que são parte da vida das crianças pequenas, superamos a equivocada ideia de que ela é apenas um tempo-espaço de preparação para a vida adulta. Nesse sentido, consideramos fundamental conceituar o desenvolvimento humano como um processo no qual as pessoas se transformam por meio da sua participação contínua em atividades culturais, em um processo vinculado à relação dos indivíduos com seus contextos (Rogoff, 2005). Desse modo, redimensionamos a ideia do bebê visto como alguém que precisa crescer para participar. Defendemos que, pelo contrário, é participando que o bebê cresce, aprende e se desenvolve ao habitar contextos de vida coletiva.

\section{Análises: o grupo do berçário na vida coletiva da creche}

A partir do objetivo de investigar como a presença de um grupo de berçário nos espaços de uso comum de uma escola de educação infantil do RS pode implicar redimensionamentos pedagógicos, a análise dos dados construídos foi organizada em dois eixos. O primeiro trata da ampliação das experiências dos bebês, com ênfase nas aprendizagens construídas no contato com a natureza e com outros sujeitos e, também, discute como essas ações e relações dos bebês estabelecidas no coletivo da creche dão visibilidade à ação pedagógica do berçário. Já o segundo eixo de análise aborda como a presença dos bebês, para além da sala do berçário, traz provocações acerca do modo como a instituição de Educação Infantil está organizada, nos fornecendo indicativos de que precisamos reorganizá-la para melhor acolhê-los.

\section{Encontros com a natureza e outros sujeitos na ação pedagógica com bebês}

O primeiro eixo de análise refere-se aos encontros dos bebês com a natureza e com outras crianças e adultos da instituição. Esses encontros eram propiciados com a sua circulação e presença nos diversos espaços da creche que eles frequentavam, assim como com a consequente visibilidade de suas ações no coletivo e o redimensionamento da ação pedagógica no grupo do berçário.

A partir da recorrência dos eventos observados, destacamos os encontros dos bebês com a natureza, os quais presenciamos nos três pátios da instituição que frequentavam. Em relação a esses contatos das crianças com ambientes externos, Mantovani, Braga e Gambini (2016) argumentam sobre o valor educativo do contato direto com a natureza e sobre as atividades desenvolvidas nas áreas abertas: bemestar; movimento físico e emocional; desenvolvimento sensorial, motor, afetivo e social; autonomia e espírito de aventura; amor à natureza e compromisso com a sustentabilidade ambiental. 
Nesse sentido, conectamos esses preceitos às experiências dos bebês que acompanhamos nos pátios, como sentir a brisa do ar, acompanhar os raios do sol e a poeira que "dança" neles, escutar os barulhos, acompanhar com o corpo o movimento dos aviões, procurar formigas e outros pequenos insetos de jardim no chão, tocar as folhas e experimentar as suas texturas, equilibrar-se em um nos desníveis do chão de terra, engatinhar na grama, sentir o cheiro das frutas das árvores e prová-las, explorar a areia, encher e esvaziar baldes, entre outras.

Na relação com elementos da natureza, os bebês pareciam fazer-se perguntas: o que é? Por que se mexe? Onde mora? O que come? Que cheiro tem? Assim, mostravamse desejosos por explorar os pátios e os seus elementos. A atenção dos bebês e os percursos de exploração das plantas e dos seres vivos nos remetem à imagem de bebê capaz, e às perguntas e inquietações que são características dos primeiros anos de vida: "O que é isso?" e "O que eu posso fazer com isso?" Tais questionamentos são centrais nos momentos do brincar heurístico e do jogo livre (Goldschmied \& Jackson, 2006), e também nos pareceram estar presentes nos encontros dos bebês com a vida na natureza. Esses processos são reconhecidos como importantes experiências de aprender dos bebês, na medida em que respeitamos os seus tempos enquanto eles se relacionam com os mistérios da natureza.

A sensibilidade em direção ao ambiente pode vir de um conhecimento baseado sobre "relação com", sobre a capacidade de ficar no tempo que for necessário a explorar, refletir, discutir e aprofundar, pouco favorecida no atual contexto social onde predomina a velocidade dos processos, a fragmentação as experiências, a tendência a fornecer uma superabundância de informações difíceis de confiscar e processar, onde não há um tempo equilibrado entre experiências virtuais e reais, o representado e o vivido (Mantovani et al., 2016, p. 66)

Além da relação dos bebês com a natureza presenciada nos três pátios da escola, percebemos que a circulação pela creche permitia o contato com outras pessoas - tanto com as crianças de outras idades como com os adultos pelos corredores e espaços de uso comum. Também proporcionava o contato com o acervo de brinquedos e materiais na brinquedoteca, assim como o manuseio e a exploração de livros infantis, fantoches e outros materiais próprios da biblioteca, entre outros espaços. Contudo, compreendemos que não se trata de preencher as jornadas, os dias, os tempos, muito menos os espaços com "atividades" a realizar, mas valorizar o que emerge do cotidiano, na riqueza dos encontros entre os bebês, dos bebês com as crianças e dos bebês com os adultos e com tantas materialidades diversificadas.

Esse exercício de análise exigiu que estivéssemos atentas a situações sutis e pouco exploradas, que surgem quando não se limita a vivência num único espaço entre quatro paredes, e nos levou a uma reflexão da natureza cultural da vida cotidiana. Entre tantos aspectos, destacamos os encontros dos bebês com crianças de outras idades e as interações que se estabeleciam. Nessa direção, as fundamentações de Rogoff (2005) de que as pessoas se desenvolvem "como participantes das comunidades culturais", possibilitou-nos valorizar aquilo que os bebês aprendem no contexto de 
vida e com a ajuda daqueles que os cercam.

Por exemplo, nos momentos de alimentação, presenciamos as crianças mais velhas interagindo com os bebês, compartilhando cuidados para com eles, vivenciando o momento de alimentar-se como oportunidade de convívio social, o qual está permeado de significados culturais, interações e trocas entre os sujeitos. Nesses momentos, assim como em outros no pátio, percebemos relações pautadas por brincadeiras; os bebês se apropriavam de formas de agir das crianças mais velhas, na medida em que agiam de modo semelhante, e vice-versa.

Para ampliar essa visão da natureza cooperativa da aprendizagem da qual Rogoff fala, a autora aponta outro conceito que compreende como central em sua teoria: o da "participação orientada" em atividades culturais (2005). As crianças aprendem de várias formas, à medida "que participam e são orientadas pelos valores e pelas práticas de suas comunidades culturais". Quanto ao termo “orientada”, esse conceito:

[...] é utilizado de forma ampla, para incluir interações cuja intenção é instrutiva, mas ir além delas. Além dos instrutivos, a participação trata de sistemas de interação paralela ou distal, nos quais as crianças participam dos valores, das habilidades e das práticas de suas comunidades, sem intenção instrutiva, ou mesmo sem estar juntas, ao mesmo tempo. Ela inclui formas variáveis de participação em atividades culturalmente orientadas [...]. (Rogoff, 2005, p. 233)

Com inspiração nesse conceito, queremos sublinhar o quanto os bebês — assim como crianças mais velhas e adultos — aprendem na relação com outras crianças, na vida cotidiana, por meio de suas experiências no dia a dia, e não apenas em situações formais dirigidas pelo professor e centralizadas em conhecimentos sistematizados. As aprendizagens de 0 a 3 anos são vitais, difusas e dizem respeito a muitos aspectos: o controle dos movimentos e do próprio corpo da criança, o aprender a falar e exprimir suas emoções, relacionar-se com os outros, conquistar autonomia e realizar as primeiras experiências de cidadania. Isso ocorre em processos nos quais as crianças pequenas são "pequenos mentores" dos seus pares, e o ensino não está centrado no adulto (Mantovani, 2016).

Nessa direção, os dados acima analisados contrapõem-se ao tradicional uso da sala das turmas no ensino fundamental e a sua configuração como local privilegiado para as aprendizagens, que infelizmente vem incidindo também nas práticas com crianças bem pequenas. Sacristán (2005) critica o uso excessivo das "salas de estar", alertando quanto ao tempo que nelas se permanece: trata-se de um espaço que tão pouco pode oferecer às crianças em relação ao mundo que há do lado de fora. Alerta que, cheia de mesas, a sala impede grandes movimentações, contemplando apenas um estreito repertório de ações.

Concordamos com a crítica do autor ao transportá-la para as salas de berçário: embora não sejam espaços repletos de mesas e cadeiras, muitas vezes são configurados apenas por berços e cercadinhos. Nesse contexto, permanecer uma jornada inteira 
em espaços como esses limita as oportunidades das crianças. Sob essa ótica, na cultura escolar a primazia da sala de aula (ou sala do grupo) está ligada a uma ideia de aprendizagem que se faz com o corpo disciplinado, sentado, quieto, priorizando as aprendizagens tidas como cognitivas, no sentido restrito do termo, e reduzindo-as aos conteúdos escolares. No entanto, no contexto investigado, encontramos justamente o oposto, ou seja, evidências da potência de todos os espaços da creche como contextos educativos que promovem a ampliação de experiências e o desenvolvimento integral dos bebês.

Outro aspecto interessante é que, nesses movimentos de circulação do grupo do berçário pela creche, ao irem e virem e estarem nos espaços, fomos percebendo que a ação dos bebês e os seus fazeres na creche tornavam-se mais visiveis na instituição. Enquanto os bebês estavam investigando curiosidades da natureza nos pátios, brincando na areia, brincando com seus pares, pintando, correndo ou brincando pelos cantos temáticos no hall de entrada, havia outras pessoas passando pelos espaços - funcionários, professores e crianças maiores.

Como exemplo, trazemos a seguir um episódio observado no corredor ao lado da sala do berçário, em um dia em que a professora convidou os bebês para pintar. Se, por um lado, estar no corredor pintando permitia que os bebês vissem a natureza pelas paredes e janelas de vidro presentes em toda a extensão do corredor, por outro destaca-se o fato de que aquilo que os bebês faziam no corredor também era visto pelas outras pessoas que circulavam na instituição. Alguns comentários registrados no diário de campo fundamentam e ilustram essa visibilidade dos fazeres do bebês:

- Olha, os bebês fazendo arte! (Menina de 4 anos, do Jardim A)

- Olha que amor, ali! (Menino de 5 anos, do Jardim B)

- Tinha que tirar uma foto deles, né professora? (Cozinheira)

- Nossa, professora! Eu fico impressionada com a sensibilidade dos bebês... que nem naquele dia em que estavam pintando... imagina! Olha a sensibilidade deles! (Funcionária de serviços gerais)

- Cuidado que os bebês estão pintando no chão! Vamos passar pelo ladinho... (Professora do Jardim B) (Diário de campo, 05 de agosto de 2010)

Habitar espaços coletivos na creche também proporcionava uma visibilidade do trabalho pedagógico com os bebês e fomentava a construção de relações de respeito. Por exemplo, a última fala transcrita, da professora do Jardim, foi no momento em que alguns bebês pintavam no corredor e um grupo de crianças maiores passava por ali. Na ocasião, percebemos que as crianças mais velhas ficaram olhando com interesse o que os bebês estavam fazendo, conversando com eles e desviando para não pisar nas pinturas que estavam no chão. Assim, mostravam como, no convívio, podem aprender a respeitar umas às outras.

Nas cinco primeiras falas transcritas, evidenciamos que os bebês, ao participarem dos outros contextos de vida coletiva da instituição além da sua sala, frequentando diversos espaços, agindo e interagindo neles, ajudam a construir outras imagens sobre 
o que podem, por meio do convívio com as pessoas daquela instituição. Essa análise só foi possível na medida em que se concebeu a escola como lugar socialmente construído nas e pelas relações que ali se constituem - portanto, um local que não é fixo ou estanque, mas que está em constante transformação. Também, parte-se da perspectiva de que as crianças são atores na construção de sua vida social e da vida daqueles que as rodeiam (Montandon, 2001).

No caso do pátio da frente (espaço onde os bebês eram vistos também pela comunidade), presenciamos pessoas que passavam pela rua exclamando: "Olha, de todas as idades!", demonstrando espanto ao verem os bebês naquele espaço. Contudo, descrevemos abaixo uma cena que ocorreu envolvendo funcionárias da creche:

Hoje no pátio da frente, quando duas funcionárias chegavam à escola, ficaram paradas em frente ao portão, olhando os bebês que brincam ali perto. Guilherme está em pé, apoiado nas grades, Diogo e Amanda estão brincando na grade de ferro. Nisso, uma delas se movimenta para entrar na escola, e a outra diz "Espera, olha os bebês! Espera aquele caminhar!", para que a outra não empurre o portão e atrapalhe o que os bebês estão fazendo, sendo que Gui está se apoiando bem na parte da grade de ferro (a qual é móvel para que o portão se abra). Então, elas esperam Guilherme lentamente percorrer o trajeto correspondente ao portão, para só depois abri-lo.

(Diário de Campo, 08 de maio de 2010)

Essa cena nos chama atenção, pois geralmente há uma tendência de intervenção do adulto no que o bebê faz, no sentido de achar que precisa completar suas ações, ou complementá-las numa dimensão de que ele precisa da sua ajuda o tempo todo. Muitas vezes, isso ocorre numa perspectiva que interrompe as suas ações, como se elas não tivessem valor, significado ou importância. Sem acreditar que o bebê também se concentra nas atividades que realiza, que se engaja nos seus atos de descoberta e investigação do mundo, tanto faz interferir no que ele está fazendo ou permitir que continue a fazê-lo. Porém, o que ocorre no episódio acima analisado é justamente o contrário: a espera do adulto para não interromper o que o bebê está fazendo, o reconhecimento das capacidades dos bebês e o respeito ao seu tempo e às suas aprendizagens.

Em suma, a análise desse conjunto dos dados da pesquisa revelou como a prática pedagógica de circular com os bebês pela escola complexifica e amplia as possibilidades de exploração e de aprendizagens a eles propostas. Afirmamos isso porque cada espaço criou novas formas de ação, experiências e brincadeiras, enriquecendo a jornada diária do grupo e possibilitando encontros com distintos elementos materiais e humanos (Barbosa, 2006). Ao mesmo tempo, habitar espaços de uso comum possibilitava um redimensionamento da ação pedagógica com os bebês e conferia visibilidade ao trabalho desenvolvido no berçário. 


\section{As provocações que se instalam com a presença dos bebês}

O segundo eixo de análise trata das provocações que o grupo de bebês, em suas ações e relações, colocava à estrutura escolar, ao circular e frequentar os espaços da creche, no que se refere a três aspectos: as suas (não) marcas permanentes nesses espaços; a necessidade de um trabalho conjunto dos profissionais da escola para atender ao grupo do berçário; o convite a romper com modos de funcionamento institucional estabelecidos a partir das turmas das crianças mais velhas.

Nessa perspectiva, o verbo "provocar" está sendo entendido como ação que nos incita a repensar e aprimorar as práticas desenvolvidas, desacomodando formas de organização já instauradas. Aqui, no segundo eixo de análise, as provocações a que nos referimos são relacionadas à organização pedagógica institucional, para que esta dê conta das especificidades dos bebês, das infâncias, de seus direitos.

A primeira provocação é sobre as (não) marcas dos bebês. As marcas dos bebês nos espaços de uso comum que eles ocupavam na creche se configuravam como efêmeras e passageiras. Ainda que a sua presença constante já tivesse provocado algumas mudanças estruturais nos espaços da instituição pesquisada (por exemplo, no refeitório), consideramos que faltava aquilo que Schmitt chamou de mais "[...] elementos que sejam identificadores da presença dos bebês" (2008). De modo geral, os espaços que são usados por vários grupos nas escolas costumam ser imparciais, não apenas no que tange à prática educacional com bebês. O mesmo ocorre com outros espaços em nossa sociedade que contemplam uma rotatividade de usuários.

Quanto à adequação da estrutura dos espaços de uso comum da escola pesquisada para receber o grupo do berçário, na opinião da professora, esses locais estavam preparados, mas mesmo assim foi possivel perceber que ela e as outras educadoras costumavam levar alguns materiais mais apropriados às suas especificidades. Essa constatação é evidenciada em sua fala: "Tu viu? O tapete é itinerante!", ou quando a monitora se posiciona e diz: "Eu só vou [ao pátio] se puder levar eles e os colchões!" (Diário de Campo, 26 de junho, 2010).

Nesse sentido, percebeu-se o envolvimento das educadoras em qualificar as visitas e a presença dos bebês aos espaços. Isso ficou evidente quando, pensando no bemestar dos bebês menores, elas levavam o tapete, as almofadas, os brinquedos, os pneus forrados, uma manta para que os bebês menores pudessem ser tirados dos carrinhos, dentre outros materiais. Em meio a essas simples ações, percebemos que no cotidiano dessas visitas existiam algumas marcas passageiras. A essas marcas chamamos de marcas itinerantes do grupo do berçário, referindo-nos aos elementos que iam e voltavam dos espaços junto com os bebês.

Rosemberg (2015b) problematiza essa questão da adequação dos espaços para acolher os bebês no contexto da cidade, indicando que estes parecem não pertencer à nação. Assim, a autora nos faz refletir sobre como o espaço público urbano é 
hostil aos bebês. Ela destaca que as condições das vias públicas são inapropriadas para transitar com carrinhos de bebê nas calçadas ou mesmo no transporte público. A pesquisadora alerta ainda sobre a falta de brinquedos adequados aos bebês nas praças e parques, entre outras questões, convocando-nos a pensar nas condições de cidadania dos bebês.

Relacionando os apontamentos de Rosemberg com a nossa pesquisa, a análise dos dados nos levou a entender que organizar os espaços de uso coletivo de forma que contemplem ainda mais as características e especificidades do grupo de bebês é um desafio social, não se restringindo às creches. Todavia, parece que isso só se tornará uma adequação necessária e entrará na pauta das discussões na medida em que os bebês estejam a ocupá-los. Em outras palavras, com a inclusão dos bebês, vão emergindo as necessidades de readequação dos espaços.

Na escola pesquisada, percebemos que as necessidades iam surgindo conforme o espaço era usado pelos bebês - e nesse sentido também as ideias de como adequá-los melhor às especificidades da turma do berçário. O trecho a seguir traz a conversa entre a diretora e a professora, exemplificando como os adultos vão se conscientizando das especificidades dos bebês:

Estamos no pátio da frente da escola, a diretora encontra a professora Mariana que está caminhando com o Bruno. Como ele está aprendendo a caminhar sozinho, ela está por trás dele, servindo de apoio para que ele caminhe. Nesse instante, a diretora diz: "Nós podíamos botar umas barras aqui", olhando para a lateral do pátio. (Diário de Campo, 11 de agosto de 2010)

Se levarmos em consideração que a localização dos espaços não é neutra (Barbosa, 2006), a pretensão da diretora ao planejar imprimir naquele espaço do pátio localizado na entrada da instituição uma marca permanente da presença dos bebês, com a fixação de uma barra de ferro, é um dado importante. O pátio em que ocorreu o episódio transcrito acima constitui a entrada da escola, por onde todos os que nela chegam precisam passar. Então, o comprometimento da instituição com a educação dos bebês e o esforço para adequar os seus espaços às necessidades deles passariam a ser também visíveis à comunidade.

A segunda provocação refere-se à necessidade de um trabalho conjunto. Sair da sala com um grupo de bebês com idades entre 5 e 18 meses exige atenção, cuidado e muito trabalho por parte dos profissionais - e quando envolve o subir e descer escadas, isso se complexifica. Quando o grupo estava completo, eram necessárias muitas idas e vindas das educadoras, que levavam alguns bebês até um espaço e voltavam para buscar os outros. Também na hora de retornar, uma delas precisava ficar na sala para ir recebendo os bebês, enquanto outra permanecia no espaço frequentado até que todos fossem embora dele; por fim, havia aquela que acompanhava os bebês em sua locomoção. 
Destacamos esse aspecto como uma espécie de provocação, porque os dados nos revelam que, mesmo antes de chegarem aos espaços mais distantes da sala, como o da biblioteca ou da brinquedoteca, os bebês já problematizavam a estrutura pela qual convencionalmente as escolas vêm se organizando — com base na responsabilidade de um ou dois educadores para com o seu grupo de crianças. Na contramão dessa lógica, a professora salienta em sua fala a necessidade de um trabalho compartilhado: "Eu peço ajuda pra todo mundo para poder ir lá" (Diário de Campo, 18 de agosto de 2010). Consideramos que esse é um detalhe, mas que representa um forte fator de impedimento para sair da sala com um grupo de berçário, e que nos convoca a pensar em um trabalho coletivo para que as práticas ocorram de modo prazeroso para bebês e adultos envolvidos.

Com relação a isso, nos deslocamentos do grupo, percebemos que às vezes os bebês iam ganhando a companhia de outros profissionais que auxiliavam as educadoras, ainda que não houvesse uma combinação permanente e prévia quanto a isso. Não somente nesses momentos, como também em outros, evidenciamos a cooperação das funcionárias, do secretário e das cozinheiras para com as educadoras do grupo de bebês. Dessa forma, a parceria entre professora e educadoras mostrou-se tão fundamental quanto aquela desenvolvida entre elas e o restante dos profissionais para as saídas do grupo do berçário de sua sala.

Esses dados apresentados nos lembram que o estabelecimento educacional da infância possui, além de professores, muitos outros profissionais que cuidam e educam as crianças. A educação, como um projeto coletivo e comunitário, é constituída e implementada por meio das relações entre as pessoas, e está em constante ação na escola. Todos os adultos que trabalham na creche interagem com as crianças e, desse modo, são potencialmente educadores (Brasil, 2009).

Nesses encontros entre os bebês e os outros profissionais, valores e conhecimentos sobre o mundo são construídos e conversas são realizadas, como aponta Rogoff (2005). Os bebês vivenciam os cumprimentos, as separações e os reencontros, e podem observar esses profissionais em seus fazeres na creche. No período da pesquisa, observamos que alguns bebês construíram laços afetivos com alguns desses profissionais, o que transparecia na alegria manifestada quando se encontravam. Além disso, percebemos que alguns bebês que já caminhavam procuravam os profissionais em seus espaços específicos de atuação como, por exemplo, na cozinha, onde buscavam as cozinheiras para abraçar, cumprimentar, trocar sorrisos.

A terceira provocação diz respeito ao "incômodo" com a presença dos bebês. Em algumas observações, percebemos que a circulação do grupo do berçário pela instituição pareceu incomodar um pouco algumas educadoras dos outros grupos - talvez por influenciar a organização destes. Como exemplo, isso foi observado em momentos em que a presença de um bebê fazia com que as crianças maiores saíssem da fila quando se aproximavam, ou então saíam dos seus lugares no refeitório, quebrando uma rotina de alimentação pautada na ordem e no silêncio. 
Luiza, ao sentar-se na cadeira para almoçar, derruba sem querer um brinquedo que trouxe consigo no chão. Um menino da outra turma, sentado à mesa em frente a sua, levantase, pega do chão e coloca-o na frente da Luiza em cima da mesa. Luiza, então, olha para o objeto, olha para ele, volta seu olhar mais uma vez para o brinquedo e com a mão o derruba de novo propositalmente... Ele fica olhando para ela, se levanta e mais uma vez o junta do chão. Em seguida, ela derruba de novo e dá risada, ele repete seu comportamento anterior. Novamente ela derruba, mas dessa vez percebo que ele apenas fica olhando... $\mathrm{Na}$ tentativa de entender o porquê dessa interrupção do que estava acontecendo, sigo o olhar do menino e encontro a sua professora, que está ao fim da mesa falando numa voz séria para se comportarem. (Diário de Campo, 20 de maio de 2010)

É notória no episódio acima a interação entre os bebês e as crianças maiores, bem como a brincadeira que estabelecem entre si, mas aqui vamos focar nas ações das educadoras diante disso. Nessas situações de encontro entre os grupos, percebemos que a postura da professora do berçário era singular, pois a sua reação era marcada por tranquilidade quando percebia que um bebê estava circulando pelo refeitório. Já algumas educadoras das outras turmas pareciam querer, apressadamente, separar os bebês das crianças maiores, evitando assim que ocorresse certa "bagunça" e desorganização de um modo de funcionamento já instituído entre elas.

Também identificamos isso em uma situação vivida no pátio, quando dois bebês correram ao encontro de crianças que estavam numa aula de educação física e, ao se aproximarem, a "roda" se desmanchou porque as crianças foram em direção aos bebês. Percebemos o desconforto da professora em relação a essa situação, na qual a passagem da turma do berçário pelo pátio pareceu desestruturar certa atividade que estava em andamento. Ao analisar tais dados, fica perceptível o quanto os bebês ocupam os espaços com diferentes tempos, ritmos e movimentos. No grupo do berçário, há corpos que engatinham, que andam no colo de um adulto ou que já ensaiam passos rápidos - há uma diversidade muito pulsante. Assim, os bebês problematizam a compreensão de docência que se configura com centralidade na figura do adulto e na ideia das crianças fazendo todas a mesma atividade ao mesmo tempo, andando em filas, esperando, etc.

Os bebês - com suas especificidades e características - exigem conceber outro tipo de estabelecimento educacional e, consequentemente, uma revisão do que entendemos por escola, infância e currículo (Barbosa \& Richter, 2010). Para as pesquisadoras, os bebês interrogam o que significa viver o ofício de aluno numa turma de berçário, o que se espera de uma ação pedagógica na creche e como se propõe um currículo para crianças bem pequenas.

Assim, consideramos que os bebês, por meio de suas provocações, ajudam-nos a continuarmos escapando do formato escolar para as instituições de educação infantil, e de uma educação com tempos fixos, fragmentados, homogêneos, rotinas inflexíveis, etc. (Vincent, Lahire, \& Thin, 2001). A presença do grupo do berçário, ao se confrontar com grupos de crianças maiores, inquieta e desestabiliza esse modo de funcionar da escola. Os bebês, com suas linguagens e seus comportamentos ainda 
não "formatados", trazem a criação, a alegria, as surpresas e o inesperado nos seus encontros - uma presença que assim se faz singular em meio à coletividade. Dessa forma, com suas ações e linguagens, os bebês nos lembram de que a educação infantil tem um modus operandi próprio e singular (Freitas, 2007).

\section{Considerações finais: os bebês na creche para além da sala do berçá- rio}

Ao acreditarmos que o espaço é uma categoria estruturante da e na pedagogia da pequena infância, cada espaço da instituição de educação infantil transforma-se em contexto educacional. Contudo, não podemos esquecer que os espaços provocam e desafiam, mas que há nos bebês a iniciativa de explorar, procurar, investigar. Os espaços lançam convites aos bebês, e os adultos, ao organizarem-nos, potencializam essas situações, mas são eles os roteiristas que vão construindo os seus percursos, escolhendo cantinhos para ficar, investigando, experimentando...

Assim, por um lado, uma jornada que contempla a ida dos bebês a diferentes espaços é reveladora da aposta dos educadores e do que esses espaços têm a oferecer a eles em termos de aprendizagens. Por outro, demonstra também que há uma aposta nos bebês, na sua agência, pois pressupõe uma imagem de criança bem pequena potente, que tem "o que brincar-fazer-aprender" nos diferentes espaços. Nessa perspectiva, a inclusão dos bebês como frequentadores dos diferentes espaços da escola promove, além do redimensionamento do fazer pedagógico com bebês, um redimensionamento do modo de funcionamento da escola infantil. A presença dos bebês traz à tona a diversidade dos modos de se viver o ofício de aluno, ensejando a reorganização de uma instituição mais voltada às crianças maiores.

Podemos aprender muito com os bebês nesses espaços coletivos, na medida em que nos provocam a pensar uma escola que contemple as diversidades e respeite a multiplicidade, tanto dos bebês quanto das outras crianças. Ocupar um lugar na educação infantil significa não só estar nas escolas, mas nas propostas pedagógicas, na dimensão do currículo, dos planejamentos, dos espaços e tempos, do calendário. Requer que os bebês sejam acolhidos com condições materiais, mas também em suas ações e relações com o mundo e suas interações.

A instituição de educação infantil precisa organizar-se para dar conta de todos os grupos que nela convivem, e o lugar do bebê na creche precisa ser pensado tanto na sua função política e social quanto na pedagógica. Para Arendt (2008), a efetivação da condição humana da pluralidade significa o viver como ser distinto e singular entre iguais. Pensar nas ações dos bebês mediante a ideia de singularidade e pluralidade defendida pela autora implica o reconhecimento de que eles têm características que os singularizam perante os outros. A vida coletiva na escola infantil precisa atender a singularidade tanto no que se refere às diferenças entre os próprios bebês quanto 
ao grupo de bebês com relação a outros grupos de crianças da instituição. E isso se dá na pluralidade que caracteriza a convivência humana; portanto, os espaços da creche enquanto contextos de vida coletiva precisam atender simultaneamente a singularidade e a pluralidade humana, configurando a educação infantil como contexto em que todos possam estar junto nas suas diferenças.

Trata-se de uma prática pedagógica a partir da imagem dos bebês como sujeitos que experimentam o mundo e que não estão separados do mundo, pelo contrário: são atores sociais que constroem esse mundo, estabelecendo relações com as pessoas à sua volta. É preciso habitar os espaços e redimensionar o fazer pedagógico na vida coletiva da creche, porque há muito o que se propor e planejar para além do espaço de uma sala, em espaços para brincar, experimentar e viver as infâncias.

\section{Referências}

Arendt, H. (2008). A condição humana. Rio de Janeiro: Forense Universitária.

Barbosa, M. C. S. (2006). Por amor e por força: rotinas na educação infantil. Porto Alegre: Artmed.

Barbosa, M. C. S. (2009). Práticas cotidianas na educação infantil-bases para a reflexão sobre as orientações curriculares. Brasília: MEC/UFRGS. Recuperado de http:// portal.mec.gov.br/dmdocuments/relat_seb_praticas_cotidianas.pdf

Barbosa, M. C. S., \& Richter, S. R. S. (2010). Os bebês interrogam o currículo: as múltiplas linguagens na creche. Educação (UFSM), 35(1), 85-96.

Brasil. (2009). Resolução no 5, de 17 de dezembro de 2009. Fixa as Diretrizes Curriculares Nacionais para a Educação Infantil. Brasília: MEC/SEB.

Brasil. (2006). Parâmetros básicos de infraestrutura para instituições de educação infantil. Brasília: MEC/SEB.

Freitas, M. C. (2007). Prefácio. In A. L. G. Faria (Org.), O coletivo infantil em creches e pré-escolas: falares e saberes (p. 7-14). São Paulo: Cortez.

Gobbato, C. Os bebês estão por todos os espaços: um estudo sobre a educação de bebês nos diferentes contextos de vida coletiva da escola infantil. (Dissertação (Me trado em Educação)) - Programa de Pós-Graduação em Educação, Universidade Federal do Rio Grande do Sul, Porto Alegre.

Gobbato, C., \& Barbosa, M. C. S. (2017). A (dupla) invisibilidade dos bebês e das crianças bem pequenas na educação infantil: tão perto, tão longe. Humanidades \& 
Inovação, 4(1). Recuperado de https://revista.unitins.br/index.php/humanidadesei novacao/article/view/289

Goldschmied, E., \& Jackson, S. (2006). Educação de 0 a 3 anos: o atendimento em creche. Porto Alegre: Artmed.

Mantovani, S. (2016). Prefazione. In C. Silva, E. Freschi, \& S. Mantovani (Orgs.), Didattica e nido d'infanzia. Metodi e pratiche d'intervento educativo (p. 9-11). Parma: Edizioni Junior.

Mantovani, S., Braga, P., \& Gambini, A. (2016). Incontrare i viventi: Esperienze scientifiche al Nido. In C. Silva, E. Freschi, \& S. Mantovani (Orgs.), Didattica e nido d'infanzia. Metodi e pratiche d'intervento educativo (p. 59-70). Parma: Edizioni Junior.

Montandon, C. (2001). Sociologia da infância: balanço dos trabalhos em língua inglesa. Cadernos de Pesquisa, (112), 33-60.

Rogoff, B. (2005). A natureza cultural do desenvolvimento humano. Porto Alegre: Artmed.

Rosemberg, F. (2015a). A cidadania dos bebês e os direitos de pais e mães trabalhadoras. In D. Finco, M. A. Gobbi, \& A. L. G. Faria (Orgs.), Creche e feminismo (p. 163183). Campinas: Leituras Críticas.

Rosemberg, F. (2015b). São Paulo: uma cidade hostil aos bebês. In A. Artes \& S. Unbehaum (Orgs.), Escritos de Fúlvia Rosemberg (p. 210-214). São Paulo: Cortez.

Sacristán, J. (2005). As raízes culturais da ordem escolar em que ser aluno adquire sentido. In J. Sacristán (Org.), O aluno como invenção (p. 125-190). Porto Alegre: Artmed.

Sarmento, M. J. (2007). Visibilidade social e estudo da infância. In V. M. R. Vasconcellos \& M. J. Sarmento (Orgs.), Infância (in) visível (p. 25-49). Araraquara: Junqueira \& Ma rin.

Schmitt, R. V. (2008). Mas eu não falo a língua deles!: as relações sociais de bebês num contexto de educação infantil (Dissertação (Metrado em Educação)). Universidade Federal de Santa Catarina, Florianópolis.

Simiano, L. P. (2010). Meu quintal é maior que o mundo... Da configuração do espaço da creche à constituição de um lugar de bebês (Dissertação (Metrado em Educação)). Programa de Pós-Graduação em Educação, Universidade do Sul de Santa Catarina, Tubarão.

Tura, M. de L. R. (2003). A observação do cotidiano escolar. In N. Zago, M. P. de Car- 
valho, \& R. A. T. Videlo (Orgs.), Itinerários de pesquisa: perspectivas qualitativas em sociologia da educação (p. 183-204). Rio de Janeiro: DP\&A.

Vasconcelos, T. (2007). A importância da educação na construção da cidadania. Saber (e) Educar, 12, 109-117.

Vincent, G., Lahire, B., \& Thin, D. (2001). Sobre a história e a teoria da forma escolar. Educação em revista, 33, 7-47.

Zago, N. (2003). A entrevista e seu processo de construção: reflexões com base na experiência prática de pesquisa. Itinerários de pesquisa: perspectivas qualitativas em sociologia da educação. Rio de Janeiro: DP\&A, 14, 9.

\section{Biografia}

\section{Carolina Gobbato}

Universidade Estadual do Rio Grande do Sul

Email: carolinagobbato@gmail.com ORCID: https://orcid.org/0000-0002-11267363

\section{Maria Carmen Silveira Barbosa}

Graduada em Pedagogia pela Universidade Federal do Rio Grande do Sul (1983), especialista em Alfabetização em Classes Populares pelo GEEMPA (1984) e em Problemas no Desenvolvimento Infantil pelo Centro Lidia Coriat (1995), mestre em Planejamento em Educação pela Universidade Federal do Rio Grande do Sul (1987), Doutora em Educação pela Universidade Estadual de Campinas (2000) e Pós-doutora pela Universitat de Vic, Catalunya, Espanha (2013).

Email: lica.barbosa@ufrgs.br ORCID: https://orcid.org/0000-0002-3416-4914 